\title{
Gender-related differences in critical limb ischemia due to peripheral arterial occlusive disease
}

\author{
Diferenças entre os gêneros em pacientes com isquemia \\ crítica por doença arterial obstrutiva periférica \\ Vanessa Prado dos Santos ${ }^{1}$ Carlos Alberto Silveira Alves², Cícero Fidelis Lopes³, José Siqueira de Araújo Filho
}

\begin{abstract}
Background: Mortality from cardiovascular disease has declined among men and increased among North American women. Recent studies have revealed differences between genders in the epidemiology of atherosclerotic disease. Objective: To study possible differences between male and female patients with critical limb ischemia (CLI) according to risk factors of atherosclerosis and clinical characteristics of lower limbs with peripheral arterial occlusive disease (PAOD). Methods: The study included 171 male and female patients treated for CLI due to infrainguinal PAOD and compared clinical characteristics (Rutherford category and PAOD territory), risk factors for atherosclerosis (diabetes, age, smoking and hypertension) and number of opacified arteries on digital angiograms of the leg. The EPI-INFO software was used for statistical analysis, and the level of significance was set at $p<0.05$. Results: Mean age was 70 years, and 88 patients were men (52\%). For most patients (both genders), Rutherford category was 5 ( $82 \%$ of men and $70 \%$ of women; $p=0.16)$. The group of women had higher mean age ( $73 \mathrm{vs} .67$ years; $p=0.0002$ ) and greater prevalence of diabetes ( $66 \%$ vs. $45 \%$; $p=0.003$ ) and hypertension ( $90 \%$ vs. $56 \% ; p=0.0000001$ ). Among men, the prevalence of smoking was higher ( $76 \%$ vs. $53 \%$; $p=0.0008$ ). The analysis of digital angiograms revealed that opacification of only one artery in the leg was found for $74 \%$ of women (vs. 50\% of men). Conclusion: The prevalence of risk factors for atherosclerosis and the characteristics of PAOD are different between male and female patients with CLI.
\end{abstract}

Keywords: gender, atherosclerosis, ischemia; peripheral arterial disease.

\begin{abstract}
Resumo
Contexto: A mortalidade por doença cardiovascular vem declinando entre os homens e aumentando entre as mulheres norte-americanas. Pesquisas mostraram diferenças relacionadas ao gênero na epidemiologia da doença aterosclerótica. Objetivo: Estudar possíveis diferenças entre pacientes com isquemia crítica por doença arterial obstrutiva periférica (DAOP), de ambos os gêneros, em relação à presença de fatores de risco para a aterosclerose e características da DAOP infrainguinal. Métodos: Foram incluídos 171 doentes internados com isquemia crítica por DAOP infrainguinal. Estudamos comparativamente, entre homens e mulheres, as características clínicas (Classificação de Rutherford e território da DAOP), a presença de fatores de risco para a aterosclerose (diabetes, idade, tabagismo e hipertensão arterial) e o número de artérias com alguma opacificação nas angiografias digitais da perna. A análise estatística foi realizada pelo EPI-INFO. Considerou-se significante $p<0,05$. Resultados: Dentre os 171 casos, a média de idade foi 70 anos, sendo 88 doentes do gênero masculino (52\%). A maioria dos pacientes, de ambos os gêneros, era Categoria 5 da Classificação de Rutherford (82\% dos homens e 70\% das mulheres/ $p=0,16)$. O gênero feminino apresentou média de idade mais avançada (73 VS 67 anos/p=0,0002), maior prevalência de diabetes (66\% VS 45\%/ $p=0,003$ ) e de HAS ( $90 \%$ VS $56 \% / p=0,0000001)$. Os homens mostraram maior prevalência de tabagismo ( $76 \%$ VS $53 \% / p=0,0008$ ). Nas arteriografias, $74 \%$ das mulheres (VS 50\% homens) apresentaram opacificação de apenas uma artéria na perna. Conclusão: $\bigcirc$ estudo mostrou que existe diferença entre homens e mulheres com isquemia crítica em relação à prevalência dos fatores de risco para aterosclerose e às características da DAOP.
\end{abstract}

Palavras-chave: gênero; aterosclerose; isquemia; doença arterial obstrutiva periférica.

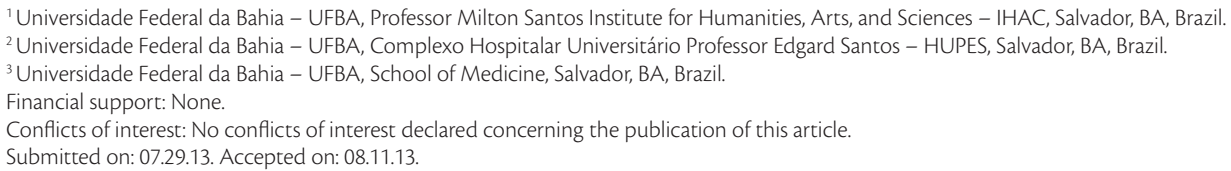




\section{INTRODUCTION}

Mortality due to cardiovascular diseases (CVD), in the United States, has been declining among men and increasing among women since the $1980 \mathrm{~s}^{1}$. In Brazil, data collected in 2007 showed that over $70 \%$ of all deaths were due to noninfectious chronic diseases, such as CVD and diabetes ${ }^{2}$. According to Brazilian studies, there has been an increase in overweight and obesity rates in the last decades, greater among women, which has affected the prevalence of diabetes, metabolic syndrome and $\mathrm{CVD}^{2}$. Current research has investigated possible gender differences in the following diseases: ischemic heart disease, peripheral arterial occlusive disease (PAOD), abdominal aortic aneurysm and carotid atherosclerosis ${ }^{1,3-9}$. Prevalence of risk factors and comorbidities may be different between men and women with PAOD ${ }^{1}$. Patients with critical limb ischemia, characterized by pain at rest, ulcer or gangrene, secondary to peripheral vascular disease, are at a high risk of CVD and limb loss ${ }^{10}$.

This study evaluated severity of clinical conditions, PAOD territory and prevalence of atherosclerosis risk factors to determine whether there are differences between male and female patients with critical lower limb ischemia due to infrainguinal PAOD.

\section{METHODS}

This study included 171 consecutive patients hospitalized in Complexo Hospitalar Universitário Professor Edgard Santos of Universidade Federal da Bahia for treatment of critical lower limb ischemia due to atherosclerotic infrainguinal PAOD. This retrospective study was approved by the Ethics in Research Committee of Complexo Hospitalar Universitário Professor Edgard Santos of Universidade Federal da Bahia. Medical charts and clinical follow-up files of patients hospitalized in the Vascular Surgery Service from December 2005 to December 2011 were reviewed to collect data.

The 171 patients included in the study had been hospitalized for treatment of critical limb ischemia. Physical examination revealed normal femoral pulses, which confirmed that the obstructive disease was infrainguinal. Exclusion criteria were hospitalization due to acute ischemia, non-atherosclerotic ischemic disease, no critical ischemia at admission and/or aortoiliac PAOD.

Patients were included if their clinical data and digital subtraction arteriograms were found in the clinical follow-up files of the Vascular Service. A protocol was prepared to collect medical information. Two vascular surgeons examined arteriograms and recorded the number of leg arteries that had any opacified segment. Patients were divided into two groups according to gender for the comparison of clinical profile, atherosclerosis risk factors and number of leg arteries with at least one opacified segment on angiograms. Patients with diabetes were those with a previous diagnosis of the disease and who were receiving treatment for it; the same criteria were used to classify patients with hypertension. For the analysis of study data, patients were classified as smokers when currently smoking.

The following factors were compared between the two groups of patients: Rutherford category of the lower extremity with critical limb ischemia ${ }^{1}$; patient report of previous diagnosis of heart disease or chronic renal insufficiency; and territory of infrainguinal PAOD according to the examination of pulses (femoropopliteal or infrapatellar). PAOD was classified as femoropopliteal when the popliteal pulse was absent, and as infrapatellar, when the popliteal pulse was palpable and normal. The correlation between prevalence of atherosclerosis risk factors (age, hypertension, diabetes and smoking) in men and women was also analyzed. The number of arteries with at least one opacified segment in the digital arteriogram of the leg, from zero to three, was recorded.

Microsoft Excel $^{\circledR}$ was used to record data, and the Epi-Info 3.3.2 software, launched in February 2005 , to analyze data. To test the association between qualitative variables of atherosclerosis risk factors, a chi-square $(\chi 2)$ test was used. Quantitative variables, such as age, were compared using analysis of variance (ANOVA). The level of significance was set at $5 \%(\mathrm{p}<0.05)$ to reject the hypothesis of no difference in study variables between genders.

\section{RESULTS}

Eighty-eight $(52 \%)$ patients were men, and 83 (48\%), women. Ninety-five patients $(56 \%$ of the sample) had diabetes, and 124 (73\%), hypertension; 111 were current smokers. The Rutherford ${ }^{1}$ category of chronic critical limb ischemia was 5 for $76 \%$ of the patients, 6 for $17 \%$ and 4 for $7 \%$. The characteristics of the 171 patients are shown in Table 1 . The mean duration of lesion in patients classified as Rutherford 5 or 6 before treatment was 92 days.

The comparison of the several PAOD risk factors between male and female patients revealed that women had a mean age significantly greater and a greater prevalence of diabetes and hypertension (Table 2). Men had a greater prevalence of current smoking. The risk factors (diabetes, hypertension 
and smoking) were grouped and compared according to number of risk factors. Among women, $82 \%$ had two or three risk factors; among men, that rate was $64 \%$. The analysis of PAOD territory revealed that women had a proportionally greater occurrence of femoropopliteal disease (84\%) than men (Table 2). Although most men had femoropopliteal disease (66\%), they had a proportionally greater occurrence of only infrapatellar occlusive lesions, with normal popliteal pulses at physical examination (34\% of the cases). The severity of clinical condition, assessed

Table 1. Characteristics of the 171 patients with critical limb ischemia due to peripheral arterial occlusive disease (PAOD).

\begin{tabular}{llc}
\hline \multicolumn{2}{c}{ Sample characteristics (171 cases) } & $\mathrm{N}(\%)$ \\
\hline Gender & Male & $88(52 \%)$ \\
& Female & $83(48 \%)$ \\
Mean age & & 70 years \\
Heart disease & & $30(18 \%)$ \\
Diabetes mellitus & & $95(56 \%)$ \\
Hypertension & & $124(73 \%)$ \\
Current smoking & & $111(65 \%)$ \\
Chronic renal insufficiency & & $13(8 \%)$ \\
PAOD territory & Femoropopliteal & $128(75 \%)$ \\
& Infrapatellar & $43(25 \%)$ \\
Rutherford & Category 4 & $12(7 \%)$ \\
& Category 5 & $130(76 \%)$ \\
& Category 6 & $29(17 \%)$ \\
\hline
\end{tabular}

according to the Rutherford category, was not different between genders. The comparison of the male and female characteristics is shown in Table 2. Duration of ischemic lesion on the foot before hospitalization was 85 days for men and 99 days for women ( $\mathrm{p}=0.18$ ).

The digital subtraction arteriograms included in the study showed that $74 \%$ of the women had only one opacified artery in the leg $(\mathrm{p}=0.005)$, whereas the same was found in only $50 \%$ of the men. Only $2 \%$ of the women and $10 \%$ of the men had at least one opacified segment in any of the three leg arteries (Table 3).

\section{DISCUSSION}

Cardiovascular diseases (CVD) are the main cause of death in the Brazilian population ${ }^{2}$, and the study of the characteristics of patients with PAOD may help us to find epidemiological data that contribute for the development of preventive measures. Differences in CVD between genders have been described in the literature. The analysis of men and women with abdominal aortic aneurysms (AAA) revealed that women seem to have a lower percentage of collagen in the aortic wall, whereas men have a smaller amount of elastin ${ }^{4}$. Anatomic characteristics and mean age of men and women treated for AAA also differed in a study that followed

Table 2. Comparative analysis of male and female patients according to clinical characteristics and risk factors of peripheral arterial occlusive disease (PAOD).

\begin{tabular}{|c|c|c|c|c|}
\hline \multirow{2}{*}{\multicolumn{2}{|c|}{ Characteristic }} & Male (88 patients) & Female (83 patients) & \multirow{2}{*}{$\mathrm{p}$} \\
\hline & & $\mathrm{N}(\%)$ & $\mathrm{N}(\%)$ & \\
\hline Mean age & & 67 years & 73 years & 0.0002 \\
\hline Diabetes & & $40(45 \%)$ & $55(66 \%)$ & 0.003 \\
\hline Currently smoking & & $67(76 \%)$ & $44(53 \%)$ & 0.0008 \\
\hline Hypertension & & $49(56 \%)$ & $75(90 \%)$ & 0.0000001 \\
\hline \multicolumn{5}{|l|}{ PAOD territory } \\
\hline & Femoropopliteal & $58(66 \%)$ & $70(84 \%)$ & \\
\hline & & & & 0.002 \\
\hline & Infrapatellar & $30(34 \%)$ & $13(16 \%)$ & \\
\hline \multirow{4}{*}{$\begin{array}{l}\text { Number of } \\
\text { risk factors * }\end{array}$} & 0 & $4(4 \%)$ & $1(1 \%)$ & 0.043 \\
\hline & 1 & $28(32 \%)$ & $14(17 \%)$ & \\
\hline & 2 & $40(46 \%)$ & $44(53 \%)$ & \\
\hline & 3 & $16(18 \%)$ & $24(29 \%)$ & \\
\hline \multicolumn{2}{|l|}{ Heart disease } & $16(18 \%)$ & $14(17 \%)$ & 0.41 \\
\hline \multicolumn{2}{|c|}{ Chronic renal insufficiency } & $8(9 \%)$ & $5(6 \%)$ & 0.23 \\
\hline \multirow[t]{3}{*}{ Rutherford category } & Category 4 & $4(4 \%)$ & $8(10 \%)$ & 0.16 \\
\hline & Category 5 & $72(82 \%)$ & $58(70 \%)$ & \\
\hline & Category 6 & $12(14 \%)$ & $17(20 \%)$ & \\
\hline
\end{tabular}

*Only three risk factors were included: diabetes, hypertension and current smoking. 
Table 3. Comparison of number of leg arteries visualized on digital angiograms of male and female patients with critical limb ischemia due to infrainguinal PAOD.

\begin{tabular}{cccc}
\hline \multirow{2}{*}{$\begin{array}{c}\text { Number of } \\
\text { opacified arteries* }\end{array}$} & $\begin{array}{c}\text { Male } \\
\text { (88 patients) }\end{array}$ & $\begin{array}{c}\text { Female } \\
(83 \text { patients) }\end{array}$ & \multirow{2}{*}{$\mathrm{p}$} \\
\cline { 2 - 3 } & $\mathrm{N}(\%)$ & $\mathrm{N}(\%)$ & \\
\hline 0 (none) & $3(3 \%)$ & $0(0 \%)$ & 0.005 \\
1 & $44(50 \%)$ & $61(74 \%)$ & \\
2 & $32(37 \%)$ & $20(24 \%)$ & \\
3 & $9(10 \%)$ & $2(2 \%)$ & \\
\hline
\end{tabular}

*At least one segment of leg artery (anterior tibial, posterior tibial or peroneal artery).

up patients that underwent endovascular repair ${ }^{5}$. Those authors evaluated the occurrence of medialintimal thickening in the common carotid arteries and found that the difference between men and women decreased after age 65 years 9 .

In the United States, studies showed that ischemic heart disease in women occurs ten years later than in men, and that when it does, women have more associated chronic comorbidities ${ }^{1}$. Our study found a similar trend among women with advanced PAOD. The prevalence of PAOD increases with age ${ }^{3}$. In our sample, women were a mean six years older than men and had a greater prevalence of diabetes and hypertension. Other authors found that women hospitalized due to acute myocardial infarction were older than men ${ }^{9}$. Lindgren et al., however, found no significant differences in mean age between patients of both genders who underwent angioplasty of the superficial femoral artery due to PAOD ${ }^{6}$. Those authors included patients with claudication in their sample and found a significantly higher percentage of critical ischemia among women that underwent treatment than among men ${ }^{6}$.

The higher prevalence of hypertension among women was also found by other authors in studies about $\mathrm{CVD}^{8,9,11}$. Su et al. found an increase in the prevalence of hypertension among women after menopause $^{9}$. In 2008, Brazilian estimates indicated that $24 \%$ of women and $17 \%$ of men older than 20 years had a diagnosis of hypertension.

Diabetes was also more prevalent among women in our sample. Fewer than half (45\%) of all men had diabetes, compared to $66 \%$ of women. Diabetes, a risk factor with a high impact on atherosclerosis in women, increases the risk of CVD three to seven times among women and two to four times among men $^{1}$. CVD is more frequent among women with diabetes $^{12}$. A Brazilian study about the prevalence of chronic diabetes complications found that 58\% of the 927 patients included were women, and the overall prevalence of peripheral vascular disease was $33 \%{ }^{13}$. The higher prevalence of diabetes among women, particularly among elderly women, has been confirmed by other authors ${ }^{11}$. In contrast, two studies that evaluated patients treated for infrainguinal PAOD using an endovascular approach found no significant differences in the occurrence of diabetes among men and women ${ }^{6,7}$. This sample included only patients with critical ischemia, and most had gangrene lesions in the foot, a sign of advanced PAOD and of a clinically more severe condition.

In our study, only smoking was more prevalent among men, which is in agreement with other studies that also found a greater frequency of smoking among men with peripheral and atherosclerotic carotid diseases $^{6-8}$. As our study was retrospective, only current smoking was analyzed. We had no accurate information about the number of cigarettes or details about previous smoking habits or abstinence duration.

In the United States, two of each three women have at least one risk factor for ischemic heart disease $^{1}$. In our study, which included only cases of critical ischemia due to PAOD, women had a higher number of risk factors than men when the three main PAOD risk factors were analyzed: diabetes, hypertension and smoking. Only one or none of these three comorbidities was found for $36 \%$ of the men, but only for $18 \%$ of the women. Among patients that also had heart disease, Scherr et al. found a greater percentage of women with more than two atherosclerosis risk factors ${ }^{11}$.

Our study investigated possible differences between men and women with advanced PAOD and critical ischemia and correlated gender with aspects of peripheral atherosclerotic disease, a topic about which there are few studies in the Brazilian literature. Patients with critical limb ischemia have a mortality of about $20 \%$ in the first year after disease onset ${ }^{10}$, mostly due to CVD. Only a small percentage of our male and female patients presented with a previous diagnosis of ischemic heart disease or chronic renal disease. If performed, tests to investigate CVD might have revealed a greater prevalence of undiagnosed heart disease in our sample. In Brazil, the AFIRMAR study found that the main risk factors for acute myocardial infarction are smoking, diabetes and central obesity; the first two were prevalent in our sample, which indicated that our patients had a high risk of heart diasease ${ }^{14}$.

The diagnosis based on the physical examination of pulses revealed that most of our patients, in both groups, had femoropopliteal PAOD. The use of a 
clinical criterion to determine PAOD territory is based on the idea that advanced superficial femoral artery disease with critical stenosis or occlusion is present when the popliteal pulse is absent. A full popliteal pulse, however, suggests that there is no hemodynamically significant stenosis of the superficial femoral artery. In addition to the clinical criterion, we evaluated angiograms and compared only data about the number of leg arteries that had at least one opacified segment. Most of our cases of femoropopliteal disease showed several opacified segments, and the femoropopliteal and infrapatellar territories were affected; only two women had opacified segments in the three leg arteries on angiograms. Clinically-diagnosed infrapatellar disease alone was proportionally more frequent among men, which indicated that a more diffuse disease, affecting both territories (femoropopliteal and infrapattelar), was found among women. Other authors suggested a more advanced degree of PAOD in women that underwent lower extremity interventions ${ }^{6,7}$.

Female patients had a smaller number of arteries visualized on the leg arteriograms, and $74 \%$ of the women only had opacified segments in one of the three arteries (anterior tibial, posterior tibial or peroneal artery). Lindgren et al. studied patients that underwent invasive treatment for infrainguinal PAOD and found that women had longer atherosclerotic lesions of the superficial femoral artery and a greater tendency to need treatment of the arteries below the knee $^{6}$. Atherosclerotic coronary lesions in women have a different anatomic pattern from that found in men and a worse prognosis ${ }^{1}$. Nguyem et al. conducted a multicenter study and found that, among patients with critical ischemia that underwent revascularization, black women had the highest risk of limb loss ${ }^{15}$. We did not study the possible correlations between female gender and limb loss or mortality. In heart disease, prognostic differences associated with gender may be secondary to greater prevalence of diabetes, obesity and dyslipidemia among women ${ }^{1}$. The loss of protections against heart disease among older women may be correlated with a fall in estrogen levels ${ }^{12}$. Studies show an acceleration of atherosclerotic disease after menopause and an increase of CVD risk factors in women older than 55 years 9 .

Some of the limitations of this study are to its retrospective design and the fact that data about body mass index, dyslipidemia and laboratory test results, such as LDL levels, were not collected. Despite those limitations, our findings revealed differences between male and female patients with advanced chronic peripheral ischemic disease according to their clinical profiles (age, hypertension, diabetes). Future studies should further investigate the consequences of such differences between genders in PAOD and their possible impact on prognosis.

In conclusion, our findings suggest that clinical severity of atherosclerotic limb disease, defined according to Rutherford category, does not differ between men and women with critical limb ischemia, but women are older and have a more diffuse atherosclerotic disease. Also, in the group of patients with critical limb ischemia due to PAOD, diabetes and hypertension are more prevalent among women, whereas current smoking is more frequent among men.

\section{REFERENCES}

1. Stock EO, Redberg R. Cardiovascular disease in women. Curr Probl Cardiol. 2012;37:450-526. PMid:23047015. http://dx.doi. org/10.1016/j.cpcardiol.2012.07.001

2. Schmidt MI, Duncan BB, Azevedo e Silva G, et al. Doenças crônicas não transmissíveis no Brasil: carga e desafios atuais. Lancet. 2011;(Série Saúde no Brasil 4);61-74.

3. Selvin E, Erlinger TP. Prevalence of and Risk Factors for Peripheral Arterial Disease in the United States: Results From the National Health and Nutrition Examination Survey,1999-2000. Circulation. 2004;110:738-43. PMid:15262830. http://dx.doi.org/10.1161/01. CIR.0000137913.26087.F0

4. Tong J, Schriefl AJ, Cohner T, Holzapfel GA. Gender differences in biomechanical properties, thrombus age, mass fractions and clinical factors of abdominal aortic aneurysms. Eur J Vasc Endovasc Surg. 2013;45(4):364-72. PMid:23395130. http://dx.doi. org/10.1016/j.ejvs.2013.01.003

5. Dubois L, Novick TV, Harris JR, De Rose G, Forbes TL. Outcomes after endovascular abdominal aortic aneurysm repair are equivalent between genders despite anatomic differences in women. J Vasc Surg. 2013;57:382-9. PMid:23266281. http://dx.doi. org/10.1016/j.jvs.2012.09.075

6. Lindgren H, Gottsater A, Hermansson K, Qvarford TP, Bergman S. Gender differences in outcome after stent treatment of lesions in the femoropopliteal segment. Scand J Surg. 2012;101:177-83. PMid:22968241. http://dx.doi.org/10.1177/145749691210100307

7. Tye A, Hand DK, Tadros RO, et al. Percutaneous intervention for infrageniculate arterial disease in women may be associated with better outcomes when compared to men. J Vasc Surg. 2013;57:706-13. PMid:22885128. http://dx.doi.org/10.1016/j. jvs.2012.05.072

8. Sangiorgi G, Roversi S, Zoccai GB, et al. Sex Related Differences in carotid plaque features and inflammation. J Vasc Surg. 2013;57:338-44. PMid:23058720. http://dx.doi.org/10.1016/j. jvs.2012.07.052

9. Su T-C, Chien K-L, Jeng J-S, et al. Age- and Gender-Associated determinants of carotid intima-media thickness: a CommunityBased Study. J Atheroscler Thromb. 2012;19:872-80. http://dx.doi. org/10.5551/jat. 10728

10. Norgren L, Hiatt WR, Dormandy JA, Nehler MR, Harris KA, Fowkes FG. Inter-society consensus for the management of peripheral 
arterial disease (TASC II). J Vasc Surg. 2007;45(Suppl S):S5-67. PMid:17223489. http://dx.doi.org/10.1016/j.jvs.2006.12.037

11. Scherr C, Ribeiro JP. Gênero, idade, nível social e fatores de risco cardiovascular: considerações sobre a realidade brasileira. Arq Bras Cardiol. 2009;93(3):e54-e56. PMid:19851643. http://dx.doi. org/10.1590/S0066-782X2009000900022

12. Dantas APV, Fortes ZB, Carvalho MHC. Vascular disease in diabetic women: Why do they miss the female protection. Exp Diabetes Res. 2012;article ID 570598. PMid:22973304 PMCid:PMC3438753. http://dx.doi.org/10.1155/2012/570598

13. Scheffel RS, Bortolanza D, Weber CS, et al. Prevalência de complicações micro e macrovasculares e de seus fatores de risco em pacientes com diabetes melito do tipo 2 em atendimento ambulatorial. Rev Assoc Med Bras. 2004;50(3):263-7. PMid:15499476. http://dx.doi.org/10.1590/ S0104-42302004000300031

14. Piegas $L S$, Avezum A, Pereira JCR, et al. Risk factors for myocardial infarction in Brazil. Am Heart J. 2003;146:331-8. http://dx.doi. org/10.1016/S0002-8703(03)00181-9

15. Nguyem L L, Hevelone N, Rogers S O, et al. Disparity in outcomes of surgical revascularization for limb salvage. Circulation. 2009;6(13):123-30. PMid:19103988 PMCid:PMC2901839. http:// dx.doi.org/10.1161/CIRCULATIONAHA.108.810341
Correspondence

Vanessa Prado dos Santos

IHAC-UFBA

Rua Barão de Jeremoabo, s/n, Ondina CEP 40170-115 - Salvador, BA, Brazi Fone: (55) (71) 3283-6799

E-mail:vansanbr@hotmail.com

Author's information

VPS is an MSc and a PhD in Surgery from the School of Medical Sciences, Santa Casa de São Paulo (FCMSCSP), and Professor at the Institute for Humanities, Arts, and Sciences (IHAC) at Universidade Federal da Bahia (UFBA)

CASA is head of the Vascular and Endovascular Surgery Service and of the Medical Residency Program in Vascular and Endovascular

Surgery at Complexo Hospitalar Universitário Professor Edgard Santos, Universidade Federal da Bahia (UFBA)

CFL is an MSc in Internal Medicine from the School of, and Professor at the School of Medicine and at the Medical Residency Program

in Vascular and Endovascular Surgery at Complexo Hospitalar

Universitário Professor Edgard Santos Medicine of Universidade Federal da Bahia (UFBA)

JSAF is a Professor at the School of Medicine, and at the Medical Residency Program in Vascular and Endovascular Surgery at Complexo Hospitalar Universitário Professor Edgard Santos, of Universidade Federal da Bahia (UFBA)

Author's contributions Conception and design: VPS Analysis and interpretation: VPS, CASA, CFL Data collection: VPS Writing the article: VPS, CASA, JSAF Critical revision of the article: VPS, CASA, CFL, JSAF Final approval of the article*: VPS, CASA, CFL, JSAF Statistical analysis: VPS

Overall responsibility: VPS, CASA, CFL, JSAF Obtained funding: None.

*All authors should have read and approved of the final version of the article submitted to J Vasc Bras. 